\title{
Management and antisepsis in wound care: The experience of an Italian region (Liguria) in the treatment of older people affected by chronic ulcers
}

\author{
Aurora Parodi, ${ }^{1}$ Valeria Maria Messina, ${ }^{2}$ Teresa Cannavale, ${ }^{3}$ Stefania Sorbara,,${ }^{4}$ Andrea Francesco Pestarino,${ }^{5}$ \\ Emanuele Claudio Cozzani ${ }^{1}$ \\ ${ }^{1}$ DiSSal Dermatologic Clinic University of Genoa/Dermatologic Clinic Hospital-Policlinic San Martino IRCCS; ${ }^{2}$ Ambulatorio \\ Convenzionato, Azienda sociosanitaria ligure $3 ;{ }^{3}$ Dermatologic Clinic Hospital-Policlinic San Martino IRCCS; ${ }^{4}$ Struttura Semplice \\ Dipartimentale Dermatologia, Azienda Sociosanitaria Ligure 4 Chiavarese, Chiavari (GE); ${ }^{5}$ Struttura Semplice Dipartimentale \\ Dermatologia, Ospedale San Paolo, Azienda Sociosanitaria Ligure 2, Savona, Italy
}

\begin{abstract}
Correspondence: Aurora Parodi, DiSSal Dermatologic Clinic University of Genoa/Dermatologic Clinic Hospital-Policlinic San Martino IRCCS, Via Balbi 5, 16126 Genova, Italy.

E-mail: aurora.parodi40@gmail.com
\end{abstract}

Key words: Skin lesion; pressure ulcers; antisepsis; elderly.

Acknowledgements: The authors acknowledge Claudia Laterza, MD of Sanitanova s.r.1., responsible for medical writing and editorial assistance.

Contributions: AP has given substantial contributions to the conception and the design of the manuscript, VMM to acquisition of the data. All authors have participated to drafting the manuscript and revised it critically. All authors read and approved the final version of the manuscript. The authors report no involvement in the research by the sponsor that could have influenced the outcome of this work.

Conflicts of interest: AP is consultant for Almirall, Novartis, Pfizer, Leo Pharma, Lilly, Galderma, Angelini, Celgene, Alfasigma. The other authors have no conflicts of interest to declare.

Funding: This work has been supported by an unrestricted grant by Angelini S.p.A.

Availability of data and materials: The authors thank Health Search, a research unit of the Italian Society of General Medicine and Primary Care (S.I.M.G.), and Asl 3 (Azienda sociosanitaria ligure 3) for sharing data. All rights reserved. Any reproduction of the data, even partial, without written authorization is prohibited.

Ethics approval and consent to participate: Not applicable.

Informed consent: Not applicable.

Received for publication: 19 February 2021.

Accepted for publication: 30 June 2021.

This work is licensed under a Creative Commons Attribution NonCommercial 4.0 License (CC BY-NC 4.0).

${ }^{\circ}$ Copyright: the Author(s), 2021

Licensee PAGEPress, Italy

Italian Journal of Wound Care 2021; 5(2):76

doi:10.4081/ijwc.2021.76

\section{ABSTRACT}

Liguria is one of the Italian regions with the highest percentage of elderly people. The European Union declared the region as a "reference site", for experimenting cutting-edge solutions and assistance models in health management of elderly people. Chronic ulcers become a problem of considerable importance looking at the number of involved elderly patients and of the necessary resources for their care, as well for the impact on the patient's quality of life, due to the painful and limiting nature of the pathology. This study aims to evaluate the appropriate wound management in older people affected by chronic ulcers. A group of wound care experts operating in the Liguria region met with the aim of reviewing the epidemiology of chronic skin lesions, analyzing the diagnostic/therapeutic approach currently in use, focusing on the importance of the antisepsis in wound management. In Liguria region general practitioners reported a $3.9 \%$ prevalence of chronic skin lesions in 2018, and up to $7.35 \%$ in women over 85 years; about $90 \%$ of the lesions managed at home were pressure lesions. An overall assessment of the patient and the lesion, appropriate cleansing and antisepsis phases and a multidisciplinary management are essential to facilitate the wound's healing process among the elderly.

\section{INTRODUCTION}

According to the latest ISTAT report, as of January $1^{\text {st }}$, 2018 , the ageing index in Italy is $168.9 \%$; the ageing index is a statistical indicator used to describe the weight of the elderly population in a given population and is given by the ratio between the elderly population ( 65 years and over) and the youngest population (0-14 years); obviously values higher than 100 indicate a greater presence of elderly subjects compared with the very young. In 2019 the ageing index for Liguria was $255.8 \%$, that is, there are 255.8 elderly people for every 100 young people; the report also shows a general trend of increase in centenarians in Italy, from 11,000 to 14,000 in the past 10 years. The largest share of centenarians (105 years and over) resides in northern Italy and the region with the 
highest percentage is Liguria. ${ }^{1}$ These numbers clearly indicate that Liguria is one of the "most long-lived" regions in the world. The European Union has declared Liguria a "reference site region", one of the sites for experimenting cutting-edge solutions and assistance models in management of the health of elderly people, with the aim of guaranteeing them the best possible ageing.

To this end, experts in the wound care sector operating in the Liguria region met, with the aim of focusing on chronic skin lesions in the elderly: in fact, elderly people have a high prevalence and incidence of chronic skin lesions. These afflict $0.6-3 \%$ of the population over 60 and $5 \%$ of people over 80 . Chronic skin lesions prevalence in the community varies from $1.9 \%$ to $13.1 \% .^{2}$ The incidence of ulcers is thought to be increasing due to ageing of the population and increasing risk factors for atherosclerotic occlusions such as smoking, obesity and diabetes. In the future, about $10 \%$ of the population will develop a chronic skin lesion over the course of their lives, with an associated mortality of $2.5 \% .^{3}$ The problem of ulcers is therefore of considerable importance, because of the number of patients involved, the time and resources necessary for treatment, and the repercussions on the quality of life, due to their painful and limiting nature.

The purpose of this work is to review the epidemiology of chronic lesions and to analyze the diagnostic/therapeutic approach currently in use in Italy in order to sensitize the scientific community and develop a shared care program for patients with chronic skin lesions; in fact, chronic ulcers, especially in elderly patients and when localized in the lower limbs, may cause pain and poor quality of life, and are associated with impairment of mobility and therefore consequences on patients' social life. ${ }^{4}$

Chronic skin ulcers are defined as "chronic lesions with no tendency to heal after 3 months of appropriate treatment or that have not yet fully healed after 12 months."5 They include ischemic ulcers, venous ulcers, diabetic ulcers, bedsores, and vasculitic and neoplastic ulcers. ${ }^{6}$ Lower limb ulcers are the most frequent and are typically caused by venous or arterial insufficiency. ${ }^{7}$

The Wound Healing Society has estimated that about $15 \%$ of the elderly suffer from chronic ulcers in the United States, with a predominance of venous ulcers, pressure ulcers and diabetic foot ulcers. Every year, there are between 2 and 3 million new diagnoses of chronic ulcers of various types in America. ${ }^{8}$

In the first comprehensive study on the costs of chronic ulcers' treatment among Medicare patients in the USA (8.2 million patients) it emerged that in 2014, wound care affected almost $15 \%$ of Medicare beneficiaries at an annual cost of about 28 billion dollars. If wounds are included as a secondary diagnosis, the cost can range from 31.7 billion to 96.8 billion dollars. ${ }^{9}$

A recent study shows that the average cost of treating chronic wounds in the UK ranges from 3,000 to 7,600 $£ /$ year (per year per single lesion; however, the cost of managing an unhealed lesion is up to 4 to 5 times higher, thus taking the costs from 3,000 to $13,500 £$ /year)..$^{10,11}$

The incidence of skin lesions in the European Union is approximately 4 million and it is estimated that over $23 \%$ of patients admitted to hospitals have a pressure ulcer, often occurring during hospitalization due to an acute episode of illness/injury. In addition, 27-50\% of hospital beds are occupied by patients with pre-existing ulcers, who are at greater risk of contracting nosocomial superinfections. The cost for the National Healthcare System is decidedly significant, both in terms of economic impact and employment of human resources, as ulcer care takes up $60 \%$ of nurses' time. ${ }^{12,13}$ Moreover, treatments are only partially reimbursed in many European countries and thus early treatment of complex patients with chronic wounds and the need for intensive daily care due to multimorbidity and complications is essential. ${ }^{14}$

According to AIUC (Associazione Italiana Ulcere $\mathrm{Cu}$ tanee Onlus) 2015/16 data, ${ }^{15}$ in Italy there are about 2 million people who, during their life, suffer from various types of chronic skin lesions, with an increasing trend; $50 \%$ of involved individuals are affected in a disabling way as a result of amputations or muscle damage. While considering that these data may be affected by the care center to which the patient is referred to and the specialization of the person who entered the data, the survey shows how the average overall age of patients is 77 and there is often more than one lesion per patient (on average 1.66 lesions per patient). Very interesting figure that emerge refer to the enormous etiological variability of lesions: $28.3 \%$ pressure ulcers, $22 \%$ venous ulcers, $12 \%$ post-traumatic ulcers, $9.3 \%$ with mixed etiology, $8.5 \%$ diabetic foot, $7.0 \%$ arterial ulcers, $4.0 \%$ atypical, $4.1 \%$ vasculitic, $3.3 \%$ lymphatic and $1.6 \%$ neoplastic. A prevalence of lower limb ulcers can be found equal to $1 \%$ of the total population: of this percentage $3.6 \%$ are patients over 65 , $75 \%$ are over 70 , while $1-2 \%$ are children. Foot ulcers have an incidence that is around $10 \%$ in patients with diabetes and, since in Italy this pathology affects about 2.643 million people, there are more than 390,000 patients with ulcers of this nature, of which about 50,000 undergo amputation of the limb. ${ }^{15}$

\section{MATERIALS AND METHODS}

A scientific board, composed by four dermatologists, a general practitioner and a nurse, all based in Liguria (Italy) with high skills in wound care and expertise in wound management met in the metropolitan city of Genoa, Italy.

This board analyzed the epidemiology of chronic ulcers in older patients and discussed disparities between 
clinical practice and recommendations for the management of chronic skin lesions.

Besides clinicians discussed about how to convey the attention of the scientific community on this particular issue, looking forward to the possibility of a new shared care program.

\section{RESULTS}

According to data collected by Health Search (research unit of the Italian Society of General Medicine and Primary Care, S.I.M.G.), in Italy in 2018, the prevalence of subjects reported by primary care physicians (representative of each macro-geographical area in terms of the numerosity of the reference population) as carriers of chronic skin lesions has an incidence of 1.58 cases $/ 1,000$ inhabitants, albeit with some regional variability. The trend has been steadily increasing in recent years and the elderly population is the one most affected by the problem. In Liguria Region Health Search show a prevalence of $3,9 \%$ of chronic skin lesions in 2018 ; in particularly the range varies from $2,3 \%$ of men between 75 and 84 years to $7,35 \%$ of women over 85 years (Figure 1).

The data contained in the final report of the SIUC project published in the Italian Journal of Wound Care have shown, unequivocally, that $90 \%$ of the lesions managed in the home environment are attributable to pressure lesions. ${ }^{15}$ Moreover, $67 \%$ of ulcers were recurrent, and represented a social problem, worsened by the limited tendency to heal; $20 \%$ of skin ulcers were still open after 2 years and $8 \%$ were not healed after 5 years. In less than $8 \%$ of the cases, lesions resolved before one year, while in $47 \%$ of cases the ulcers occurred for a period ranging from 1 to 10 years, and in $45 \%$ for more than 10 years. ${ }^{16}$ With the increase in age there is a correlation of direct proportionality with the susceptibility to bedsores due to changes age-related in the skin, such as a decrease in subcutaneous adipose tissue, decreased perception of pain,

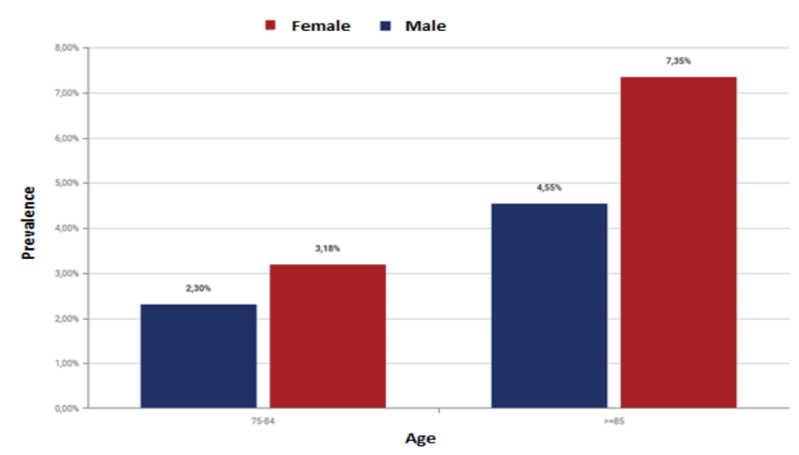

Figure 1. Prevalence of skin lesions in older people in Liguria region. reduced cell-mediated immune response, slowing down in wound healing, decreased proliferative activity of the epidermis, decreased microcirculation, reduced local inflammatory response, and decreased elasticity and sensitivity. In addition, often in the elderly patient, the above-mentioned risk factors are associated, in particular the reduction in mobility, cardiovascular diseases, diabetes and renal failure. ${ }^{17,18}$ The identification of so-called "fragile" patients - a state of greater vulnerability to changes in homeostasis or external stress factors and the establishment of immunosenescence and immunodegeneration processes - is important because they are more easily subject to chronicity of the lesion. ${ }^{18,19}$

Table 1 shows the incidence and prevalence of pressure lesions in the Liguria region's Asl 3 (Azienda sociosanitaria ligure 3) monitoring of the year 2018. Prevalence and incidence are calculated among the patients in the POU* (Presidio Ospedaliero Unico Asl 3), in the district nursing (Distretti Sociosanitari) and in the RSA nursing home (Residenza Sanitaria Assistita).

\section{MULTIDISCIPLINARY DIAGNOSTIC/THERAPEUTIC APPROACH}

The ideal management of chronic ulcers calls for a timely, strategic and coordinated approach that can provide the appropriate treatment for the individual patient. ${ }^{5}$ A comprehensive diagnostic approach that includes a vascular, metabolic and physical assessment is essential at the start of treatment for evaluating the underlying pathology. Overall, it should include: an accurate medical history with particular attention to personal, environmental and social risk factors and the presence of comorbidities by asking the patient about the perceived quality of life and the presence of pain, assessed with appropriate scales. Obviously, in the elderly the presence of an effective caregiver will be useful for assessing the ability to adhere to a prevention and treatment plan for the chronic ulcer.

Table 1. Pressure lesions in ASL3 Liguria region 2018.

\begin{tabular}{lc} 
Prevalence & $\%$ \\
\hline General Hospital POU & 8,32 \\
\hline District nursing & 43,00 \\
\hline Nursing home (>65 years) & 67 \\
\hline Incidence & $\%$ \\
General Hospital POU & 4,26 \\
\hline District nursing & 1,69 \\
\hline Nursing home (>65 years) & 42 \\
*POU (Presidio Ospedaliero Univo) are: Villa Scassi Genova Sampier- \\
$\begin{array}{l}\text { darena, Gallino Genova Pontedecimo, Padre Antero Micone Sestri Po- } \\
\text { nente, La Colletta Arenzano. }\end{array}$
\end{tabular}


Physical examination of the patient is also fundamental with particular attention to nutritional status, cognitive state, functional capacity, posture and the possible need for mobility devices. Careful examination of the skin lesion, the surrounding skin with classification of the lesion according to the guidelines should follow. Finally, the type and methods of treatment implemented or current for lesion management and related symptoms should be investigated and clarified. ${ }^{20}$

Healing of the lesion depends, in fact, on early and clear diagnosis, implementation of the treatment plan which must be adhered to and, finally, on monitoring and follow-up at pre-established deadlines. The initial and periodic assessment of wounds is a fundamental and essential aspect for achieving healing and must take into account various parameters: size of the lesion, tissue present, amount of exudate, clinical signs of colonisation and infection, stopping and/or progression of the edges, presence of pain. Reassessments enable monitoring evolution of the wound and the effectiveness of treatment. ${ }^{21}$

Chronicity of skin lesions is frequently found in patients with diabetes and vascular arterial diseases not compensated by a sufficient blood supply. Pressure induced skin lesions may be observed in elderly undergoing compression therapy, more frequently with use of high-pressure medical compression bandages in stroke patients, skin breaks, ulcers, blisters, skin necrosis and lower limb amputations. ${ }^{22}$ In addition, immunosuppressed patients, or those with organ failure, malnutrition, obesity and old age, may also present risk factors for the chronicity of wounds.

Education of healthcare professionals, caregivers and patients themselves is crucial for the healing of chronic skin lesions and careful follow-up and monitoring by competent members of the care team can substantially improve clinical outcomes, avoiding the onset of relapses and reducing morbidity and mortality related to the failed healing of acute wounds.

WHO argues that inter-professional collaboration in patient education and clinical practice is the key to providing the best care for the patient with skin wounds, improving clinical results related to the state of health and strengthening the health system. ${ }^{23}$

Team approach and patient empowerment improve health and ensure social gain, with higher levels of patient satisfaction and better acceptance of care within a collaborative team. Management of the patient who comes to hospital due to an ulcer should include their taking charge by a multidisciplinary team, which ideally consists of a nutritionist, vascular surgeon, dermatologist, radiologist, etc. and coordination of their care pathway by directing them towards suitable care settings.

Management of a well-coordinated multidisciplinary team is probably the most relevant aspect of the approach to the patient with skin lesions, because it often happens that with parceled management, in the often very long times that elapse between the visit by one specialist and the other, the ulcer worsens.

In clinical practice, an ideal approach to the management of chronic skin lesions should greatly involve family members who take care of the patient with an ulcer at home.

In the most modern and functional approach, both the family member and the patient should receive information on the pathology and training for the correct management of the ulcer, also through co-medications, although this requires the availability of personnel trained and dedicated to health education of the patient and caregivers. Furthermore, a greater awareness among the population should be aimed at health institutions, for example on the occasion of hospital admissions or through initiatives at local health authorities. In general, pressure skin lesions and diabetic foot should be treated in terms of prevention and awareness, where there is a social aggregation of the elderly, such as parishes or Universities of the Third Age, or even trade unions and social welfare bodies; basic training for the caregivers of bed-ridden elderly people or those with reduced mobility would also be useful for encouraging correct movement and an adequate nutritional intake.

Before applying the dressing to the wound it is important to implement all the procedures aimed at correcting anomalies that hinder wound healing and promote tissue repair processes. ${ }^{24}$ In fact, the initial treatment of the wounds begins with adequate cleansing and proceeds until the creation of an ideal micro-environment for healing, through various phases (haemostasis, inflammation, maturation, remodelling), with an evolution from the inflammatory to the reparative phase.

Physiologically, the reparative process consists of several phases, namely inflammation, proliferation and remodelling, in a continuum often called "healing cascade." ${ }^{25}$ When an acute skin lesion is slow in healing due to the patient's comorbidity, state of the wound or the treatment, it can turn into a chronic skin lesion, in which the environment is characterised by maintenance of the inflammatory state with an increase in proinflammatory cytokines, alteration of mitotic activity, an increase in proteases (especially metalloproteinase-2 and metalloproteinase-9 of the extracellular matrix), cell senescence, alteration of $\mathrm{pH}$ and reactive species of oxygen. ${ }^{25}$ Infection of a wound, both acute and chronic, is one of the most feared complications, mainly due to the possibility of antibiotic-resistant bacteria development; in fact, in conditions of hypoxia, necrotic tissue and slough, the ideal terrain develops for the proliferation and maintenance of the bacterial load. ${ }^{21}$ Biofilm (highly organised colonies of bacterial cells that live within a self-produced extracellular matrix) is present in $80 \%$ of chronic skin lesions and represents a negative prognostic factor, because it is often 
resistant to antimicrobial and antiseptic treatments. The presence of bacterial contamination (bioburden) of the lesion has a negative impact on the healing process and can determine persistence of the inflammatory state, favouring chronicity. ${ }^{26}$

According to the 2014 NPUAP/EPUAP/PPPIA guidelines, the treatment of ulcers should consider: ${ }^{20}$ i) optimisation of host response: assessing nutritional status and addressing its deficits; establishing glycemic control; improving arterial blood flow; reducing, when possible, immunosuppressive therapy; optimising the factors that can influence the individual response; ii) prevent contamination of the ulcer; iii) reduce the bacterial load and biofilm in the ulcer; iv) consider using antiseptics of appropriate potency, which are non-toxic and suitable for tissues, for a limited period of time to control the bacterial load.

The main steps that enable optimal management of the chronic ulcer are cleansing and antisepsis. Cleansing aims to remove foreign material (debris, dressing residue, devitalised non-adherent tissue) and reduce bioburden to promote healing. In addition to mechanical action, nonaggressive chemicals are used to improve and/or enhance the act of cleaning the wound..$^{21}$ Cleansing is one of the most important phases in the field of wound bed preparation, a series of actions that have been summarized with the acronym TIME (Tissue, Infection or Inflammation, Moisture imbalance, Epidermal margin); it should be carried out at each change of dressing and with different purposes: to remove debris and any necrotic tissue, decrease the absorption of toxins, eliminate the source of bacterial multiplication, reduce the development of microbial flora and any residuals from previous dressings, and relieve pain, making it possible to visualize the wound better for assessment. In addition to the use of physiological solution and lactated ringer, it is necessary to consider the use of solutions that can allow active cleansing, such as solutions of hypochlorous acid. Active cleansing differs from cleansing in that, in addition to the purely mechanical and humidifying action of the lesion, it allows the creation of an ideal micro-environment that favors the physiological healing process. ${ }^{27}$

The cleansing phase is followed by a disinfection phase using antiseptic solutions. Nowadays, an unmotivated use of antibiotics (both topical and systemic) may cause adverse drug effects (=ADE) and induce bacterial resistances. For this reason, the combination of antiseptics in the routine methodological approach to wound dressing could represent a significant advantage in clinical practice, allowing a more appropriate use of antibiotic therapy grounded in management protocols based on stewardship principles. The use of antiseptics such as the $0.05 \%$ sodium hypochlorite electrolytic solution (with its characteristics of rapid microbiological efficacy, tolerability and histocompatibility) is an excellent choice in the man- agement of infected wounds. ${ }^{28}$ Integration of this solution in standard treatments contributes to modulating local responses that inhibit physiological healing processes, also contributing to reduction of the bacterial load. ${ }^{27}$ For years, the local use of products such as hypochlorites has been one of the pillars of local wound treatment, ensuring high efficacy and tolerability at very low cost. Data from the literature appear to favor the application of hypochlorites at specific concentrations (such as $0.05 \%$ ) at dressing change in ulcers that are infected or have a necrotic component. ${ }^{29}$ In light of the particular efficacy/tolerability ratio documented by scientific studies, ${ }^{30}$ the guidelines suggest that the $0.05 \%$ electrolytic sodium hypochlorite solution is to be considered one of the reference solutions for the disinfection of damaged skin in the various types of chronic skin lesion, and especially in stage III and IV pressure ulcers. ${ }^{31}$

Hydrogen peroxide is considered highly toxic for tissues even at low concentrations ${ }^{32}$ and should not be used as a topical antiseptic of choice. Its use should be avoided in cavitary wounds due to the risk of surgical emphysema and gas embolism. ${ }^{33-35}$ On the other hand, iodine-based products should be avoided in patients with renal insufficiency, a history of thyroid disorders or known sensitivity to iodine. ${ }^{36,37}$ Use of acetic acid for long periods on large wounds can lead to the risk of acidosis. ${ }^{38}$ Finally, chlorhexidine is a more limited spectrum biocide; for this reason, it is often present in association with other compounds, (e.g. in association with 70\% alcohol). Over time, its wide use for the disinfection of damaged skin has led to the onset of multi-resistant germs, with cross resistance to systemic antibiotics. ${ }^{12}$

In elderly, particular attention should be paid to the prevention of recurrence through incorrect positioning; the use of atraumatic dressings to prevent and treat pressure ulcers should be favored in order to prevent damage to the skin in which the cohesion capacity of skin cells is reduced and removal of the dressing often causes detachment of the epidermal layers or detachment of the epidermis from the dermis.

\section{CONCLUSIONS}

A skin lesion that lasts for more than 3 months is considered a chronic skin lesion. The incidence of lesions is continuously increasing as a consequence of population ageing, with significant repercussions on the quality of life of patients and on the national health system. An overall assessment of the patient and the lesion is essential for determining its etiology, formulating an appropriate therapeutic plan and allowing timely intervention, but other fundamental factors must also be taken into consideration in the elderly patient such as nutrition, mobility, social and cognitive status, and the presence of an effective care- 
giver. Management of the patient affected by a chronic ulcer should be multidisciplinary and include a detailed patient history, physical examination, assessment and local management of the lesion through the essential steps of cleansing and antisepsis. Chronic wounds are heavily colonized by bacterial or fungal organisms, with the presence of dead and devitalized tissue; this entails the need to manage the bacterial load by means of adequate wound bed preparation in order to stimulate wound healing. To facilitate the wound healing process, the cleansing and antisepsis phases are essential because they allow preparation of the wound bed and control of the microbial load; for this purpose, isotonic sodium hypochlorite solution $0.05 \%$ showed efficacy and excellent tolerability on damaged skin tissues, and can be considered an excellent ally in the management of chronic lesions and in the prevention/treatment of infected wounds. Obviously in the subsequent phases, the availability of effective, affordable and user-friendly dressings is desired by patients and by the multidisciplinary care team, which should always involve and educate the patient and caregivers on the methods of dressing and on the importance of adherence to the treatment in order to ensure healing of the lesion and avoid recurrence.

\section{REFERENCES}

1. ISTAT. Rapporto annuale 2019. ISTAT: 2019.

2. Agale SV. Chronic Leg Ulcers: Epidemiology, Aetiopathogenesis, and Management. Ulcers 2013;2013:1-9.

3. Chatterjee SS. Venous ulcers of the lower limb: Where do we stand? Indian J Plast Surg 2012;45:266-74.

4. Franks PJ, Morgan PA. Health-related quality of life with chronic leg ulceration. Expert Rev Pharmacoecon Outcomes Res 2003;3:611-22.

5. Kahle B, Hermanns HJ, Gallenkemper G. Evidence-Based Treatment of Chronic Leg Ulcers. Dtsch Aerzteblatt Onlin 2011; 108:231-7.

6. Lazarus GS, Cooper DM, Knighton DR, et al. Definitions and guidelines for assessment of wounds and evaluation of healing. Arch Dermatol 1994;130:489-93.

7. Valencia IC, Falabella A, Kirsner RS, Eaglstein WH. Chronic venous insufficiency and venous leg ulceration. J Am Acad Dermatol 2001;44:401-21.

8. Markova A, Mostow EN. US skin disease assessment: ulcer and wound care. Dermatol Clin 2012;30:107-11.

9. Nussbaum SR, Carter MJ, Fife CE, et al. An economic evaluation of the impact, cost, and medicare policy implications of chronic nonhealing wounds. Value Health 2018;21:27-32.

10. Guest JF, Fuller GW, Vowden P. Venous leg ulcer management in clinical practice in the UK: costs and outcomes. Int Wound J 2018;15:29-37.

11. Guest JF, Fuller GW, Vowden P, Vowden KR. Cohort study evaluating pressure ulcer management in clinical practice in the UK following initial presentation in the community: costs and outcomes. BMJ Open 2018;8:e021769.
12. Grimaldi G, Lacaita MV, Faggiano ME. Cross-Resistenze tra antibiotici ed agenti disinfettanti: una problematica emergente. G Ital Farm Clin 2017;31:101-14.

13. Duschek N, Trautinger F. Ulcus cruris beim alten Patienten [Chronic leg ulcers in older patients]. Z Gerontol Geriatr 2019;52:377-90.

14. Cerny M, Hellmich S, Schwarz-Boeger U, et al. DRG revenues and costs of multimorbid patients in the German DRG system - Analysis of the surgical treatment of chronic wounds at a university hospital based on the example of pressure ulcers. Handchirurgie Mikrochirurgie Plast Chir 2018;50:284-90.

15. Petrella F, Abbritti F, Bachetti F, et al. I.S.U.S. PROJECT (ITALIAN SKIN ULCER STUDY) (1 January 2015-31 December 2016). Final data. Ital J Wound Care. 2017;1:1.

16. Callam MJ, Ruckley CV, Harper DR, Dale JJ. Chronic ulceration of the leg: Extent of the problem and provision of care. Br Med J (Clin Res Ed) 1985;290:1855-6.

17. Landi F, Onder G, Russo A, Bernabei R. Pressure ulcer and mortality in frail elderly people living in community. Arch Gerontol Geriatr 2007;44:217-23.

18. Levine JM. Clinical aspects of aging skin: considerations for the wound care practitioner. Adv Skin Wound Care 2020;33:12-9.

19. Levine JM. Historical perspective on pressure injury classification: the legacy of J. Darrell Shea. Adv Skin Wound Care 2019;32:103-6.

20. European Pressure Ulcer Advisory Panel and National Pressure Ulcer Advisory Panel PPPIA. Prevention and treatment of pressure ulcers: quick reference guide. Clinical Practice Guideline. 2014. 1-75 p.

21. Lundgren H. Positioning of advanced wound care. In: Dealey C, Hofman D, Gottrup F, Nelson EA, Vowden P. (eds). The Ewma University Conference Model. Management. 2008;8:5-10.

22. Rabe E, Partsch H, Morrison N, et al. Risks and contraindications of medical compression treatment - A critical reappraisal. An international consensus statement. Phlebology 2020;35:447-60.

23. WHO. Patient Safety Curriculum Guide: Multi-professional edition. 2011 Available from: http://apps.who.int/iris/ bitstream/handle/10665/44641/9789241501958_eng.pdf; jsessionid=D68B8D0580251B74268A8E032324F22E? sequence $=1$

24. Neri L, Fattori A, Rowan S, et al. Wound bed preparation: What is needed? Acta Vulnolologica 2015;13:179-83.

25. Warren D. Wound healing and skin integrity. Prim Heal Care 2013;23:13-13.

26. Snyder RJ, Bohn G, Hanft J, et al. Wound biofilm: current perspectives and strategies on biofilm disruption and treatments. Wounds Compend Clin Res Pract 2017;29:S1-17.

27. Ricci E. The management of chronic ulcers with an acidoxidising solution. J Wound Care 2016;25:443-50.

28. Scalise A, Torresetti M. Ruolo della soluzione elettrolitica di ipoclorito di sodio $0,05 \%$ nel moderno approccio alla gestione delle lesioni cutanee. Medicinae Doctor 2017; 24:8.

29. Messina M. Le soluzioni di ipoclorito nel trattamento delle ulcere cutanee croniche infette. Una revisione della letteratura. Acta Vulnologica 2009;7:13-19 
30. Santo G, D'Atanasio N, Capezzone De Joannon A, et al. Valutazione della attività e tossicità di una soluzione di ipoclorito di sodio elettrolitico allo $0,05 \%$ nel processo di riparazione tissutale. Gazz Medica Ital Arch Sci Med 2012;171:795-805

31. Cassino R, Ippolito AM. Chloroxidating solution vs. superoxide solution: a comparison in wound cleansing. Acta Vulnologica 2012;10:143-52.

32. Gruber RP, Vistnes L, Pardoe R. The effect of commonly used antiseptics on wound healing. Plast Reconstr Surg 1975;55:472-6.

33. Reid CJ, Alcock M, Penn D. Hydrogen peroxide--a party trick from the past? Anaesth Intensive Care 2011;39:1004-8.

34. Khan ZH, Farzan M. A fatal gas embolism following the use of intraoperative hydrogen peroxide as an irrigation fluid. Acta Med Iran 2004;42:151-3.

35. Echague CG, Hair PS, Cunnion KM. A comparison of antibacterial activity against Methicillin-Resistant Staphylococcus aureus and gram-negative organisms for antimicrobial compounds in a unique composite wound dressing. Adv Skin Wound Care 2010;23:406-13.

36. Leaper DJ, Durani P. Topical antimicrobial therapy of chronic wounds healing by secondary intention using iodine products. Int Wound J 2008;5:361-8.

37. Sibbald RG, Leaper DJ, Queen D. Iodine made easy. Wounds Int 2011;2:1-6.

38. Ward RS, Saffle JR. Topical agents in burn and wound care. Phys Ther 1995;75:526-38. 